\title{
Developing a Social Media Marketing Framework for Small-Scale Contractors in the Construction Industry
}

\author{
Chipozya Kosta Tembo, Franco Muleya*, Godfrey Kabwe Bulaya \\ Department of Construction Economics and Management, Copperbelt University, Kitwe, Zambia \\ Email: ^muleyaf@yahoo.co.uk
}

How to cite this paper: Tembo, C. K., Muleya, F., \& Bulaya, G. K. (2022). Developing a Social Media Marketing Framework for Small-Scale Contractors in the Construction Industry. Open Journal of Business and Management, 10, 77-100. https://doi.org/10.4236/ojbm.2022.101005

Received: September 30, 2021

Accepted: December 26, 2021

Published: December 29, 2021

Copyright $\odot 2022$ by author(s) and Scientific Research Publishing Inc. This work is licensed under the Creative Commons Attribution International License (CC BY 4.0).

http://creativecommons.org/licenses/by/4.0/

\begin{abstract}
Small-scale contractors have been reported to be under performing partly because they are less visible to their possible client(s) due to poor marketing. This study aimed to develop and ascertain the elements that should be included in a social media-marketing framework for small-scale contractors in the Zambian construction industry to improve their visibility consequently their marketing and performance. The framework was developed through a mixed method sequential approach using observations and a survey of 35 firms already using some form of social media marketing using a questionnaire comprising open and closed ended questions which was conducted to ascertain the components needed to promote social media marketing among small-scale contractors. For any firm to be successful in using social medial marketing; audience assessment, content generation as well as Return on Investment evaluation were found to be more relevant than influencers, tone and voice. However, monitoring of the client posts and the competition was found to be an area needing much attention for subsequent marketing.
\end{abstract}

\section{Keywords}

Social Media Marketing, Small-Scale Contractors, Framework, Zambia

\section{Introduction}

The construction industry is the backbone of many economies, with the ability to significantly contribute to the Gross Domestic Product (GDP) of a country (Pheng, 1994). For instance, the contribution of the Zambian construction industry to the national GDP stands at 9.3\% equivalent to about \$25 million (Republic of Zambia, 2017). Most construction industries are characterized by many 
small-scale contractors (Kulemeka et al., 2015) and Zambia is not an exception. The small-scale contractors are normally identified by their limited capital investment in need of financial and managerial support for their businesses to run effectively. The retention rate of small-scale contractors according to the $\mathrm{Na}$ tional Council for Construction report (2017) is very low. It was realized that small-scale contracting firms that belong to small scale contractors (grade 5 to 6), are stagnant and unable to make progress from small scale to either medium or large-scale contractor. It is evident that some firms have been in the same grade for a long time while others have had a high failure rate (Ibid). Smyth et al. (2016) noted that marketing is an integral part of project-based firms or project businesses in general and yet small and medium scale contractors fail to cope with the pressure of coexisting with the larger players in the industry due to the fact that they fail to market their ongoing projects to the public (Kapata, 2018). Marketing of services could easily be done in a cost-effective manner by the use of social media marketing, which is currently underutilized. Celuch and Murphy (2010); Järvinen et al. (2012) and Michaelidou et al. (2011) argue that despite the known benefits of digital promotions, little is known about digital marketing as a social media marketing tool for small businesses because the majority of the digital marketing literature focuses on large businesses and organizations. Andrews (2012) defines social media as a web-based platform where conversations can take place between two or more people in light of information exchange. Naranjo et al. (2011) highlight the notable way that most renowned experts in the Zambian construction industry consider social media as a person to person (p2p) type of interface and communication tool, hence they do not necessarily fully understand the extent to which it can be harnessed. This results in the underutilization of social media for marketing purposes.

The use of social media marketing can fit into a conventional construction marketing setup that can be broken down to uniquely meet the needs of a given industry or sector. Likewise, brand marketers around the globe have started using this popular platform for branded promotion and customer engagement (Mukherjee \& Banerjee, 2019). Other studies have considered some aspects of social medial marketing such as its various uses (Ahlqvist, et al., 2008), the use of information technology in Marketing (Celuch \& Murphy, 2010), the impact of social media (Hutter et al., 2013), its practicality (Charlesworth, 2014) key elements of social media marketing strategy (Blunt, 2018), a tool for sustainable growth in the Nigerian construction industry (Afolabi et al., 2018) and more recently customer attitude (Mukherjee \& Banerjee, 2019). Given the aforementioned, it was important to establish the needs and current use of social media marketing as utilized by small-scale contractors in order to develop a framework for Social Media Marketing (SMM) for small contractors in Zambia. While many related studies have been undertaken before as seen in the listed examples, none have considered developing a framework for social media marketing for construction firms specifically in Zambia making the study different and stand 
out from others. This study makes a synthesis of a holistic thought to SMM although the generalisation of the study can only be limited to small firms. This synthesis is new compared to other study as it looks at SMM holistically with a focus from a developing context as most past studies are carried out in developed countries or emerging markets. Additionally, it offers a road map of considerations for new firms to SMM or those already using SMM to its successful application.

The following objectives were outlined for the study:

- To investigate how the construction industry currently uses social media marketing.

- To identify the elements that should be in the social media-marketing framework for the construction industry.

- To develop a social media marketing framework for the construction industry.

The following section provides a review of literature about social media marketing. Literature shows that there are various subjects that contribute to the development of social media marketing framework. While the literature may be in silos, this paper bridges this gap by taking a holistic approach in developing a Social Media Marketing Framework (SMMF) to aid the use of SMM. The literature review is followed by the methodology used in the study. Explanations are offered for choices made in terms of methods and the design of the research. This is followed by the formulation of a social media marketing framework as constructed from the literature then presentation of results from the purposive observations and questionnaire survey in an effort to validate and improve the framework. The observations and survey are then discussed thereby providing a basis for conclusions and recommendations of the study.

\section{Literature Review}

\section{Social Media Marketing}

There is a notable difference between firms that market their products and/or services and those that do not. Thimmesch (2010) defines marketing as the activity, set of institutions and processes for creating, communicating, and processes for creating, communicating, delivering and exchanging offerings that have value for customers, clients, and society. Ojo (2011) observes that firms that actively market their products and services maintain a good relationship with clients, acquire contracts, increases sales and builds to maintain the image of the firm. Moreover, to have a successful business, a firm needs to engage in marketing (Pheng et al., 2016). Companies have long been using many different forms of advertisements and marketing strategies across different technologies to market their products or services to current, new and potential customers. Marketing can generally be distinguished between generic, traditional and social media marketing. The focus of this study was on social media marketing.

Social media can be defined as a place where two or more people connect to 
converse on a web-based platform (Andrews, 2012). However, there are multiple views on what social media is. Fulcher (2014) defines Social media as using either an information model or a communication model. Information model suggests that all media are social while communication models claim that media become social when communication takes place (Andrews, 2012; Fulcher, 2014). Social media can take different forms leaving the users with a personal experience (Coleman, 2013).

For social media marketing to be useful it has to be emotional (evoke excitement), useful (helpful and educational) and Visual (Blunt, 2018). Brown (2012) and Salcido (2011) state that SMM is a better mode of communication because it is capable of reaching a global audience, helps to drive traffic to website and avoids internal monitoring competitors and crisis management. The correlation between social media marketing and generic marketing is that the latter gives access to the former. All the elements in generic marketing are actually present in social media marketing except they have been altered to make them more technology applicable and generically more effective to reach the target audience in mind.

Ahlqvist et al. (2008) state that the most relevant element of social media is web 2.0 which is a variant to the already existing World Wide Web as it can be called. Web 2.0 technology serves as the foundation of the whole social media platform development (O'reilly, 2005), where content is shared within the community. This type of website emphasizes user generated content, ease of use, participatory culture and interoperability for end users (Lipita, 2016). Social media platforms are classified in different ways. Golden (2010) and Smith et al. (2012), classify social media platforms into two types based on ownership such as: firm sponsored or individual publications (e.g. blogs) and third-party forums such as Facebook, Twitter and LinkedIn. Further, few others such as Grahl (2015) classify the third-party forums as "Social networks". It has been observed that most construction firms only use third party forums making them the focus of this research. The main type of third-party forums to be tackled is social networks such as Facebook, Twitter, LinkedIn, Instagram and Pinterest (Taylor \& Strutton, 2016; Han \& Myers, 2018). Most people use social media networks and the breakdown as follows; Social networking consists of platforms such as Facebook, LinkedIn, Google+ and these platforms allow users to connect to people all over the world by sharing messages and media files with personalized settings. Of course, it is worth noting that there is no cost attached to any of these platforms because they are all free and they can be extensively used to capitalize on peer-to-peer communication (Grahl, 2015). The only related indirect cost is the purchase of data bundles for connecting to the internet for online-related usage.

It has been highlighted that social media marketing is quite different from traditional communication media used for marketing purposes. Traditional communication channels, namely, newspapers, magazines television and others, 
have unidirectional communication while in the case of social media the information flow is bidirectional, i.e., from the marketer to the customer and vice versa (Mukherjee \& Banerjee, 2019). Social media marketing is merely the digitization of generic marketing resulting in bidirectional communication (Hutter et al., 2013) with benefits of facilitation of knowledge management.

\section{Methodology}

This study followed a pragmatic approach leaning towards qualitative research because it was important to discover how small-scale contractors in the Zambian construction industry could practically use social media marketing to improve their visibility to their would-be clients in a quest to market their organizations. The literature on an SMM (social media marketing) was reviewed to formulate a framework, which could be verified through the purposive survey. The literature review was undertaken in a systematic manner using online resources. This was done by searching major data bases such as Emerald insights, Taylor and Francis, Science Direct, Google Scholar, Compendex, Google and others. The key words/ phrases used during the search were social media marketing, content for social media marketing, crisis management in social media, demerits/merits of social media, listening in social media and monitoring in social media. Once papers were identified, their abstracts were read for relevance and further reading was done for those that were found to be relevant. A sequential data collection approach was utilized starting by observing how contractors are currently using SMM and this was followed by a survey, which was used to collect data on the possible contents of an SMM framework and the cost implications arising after the formulation of the social media-marketing framework from literature. The respondents were purposively selected to only include small-scale contractors that already have some form of social media marketing on platforms such as $\mathrm{Fa}$ cebook, WhatsApp and Twitter. The study was cross sectional in nature. The data was analyzed by using descriptive statistics (percentages and frequencies) (Figure 1).

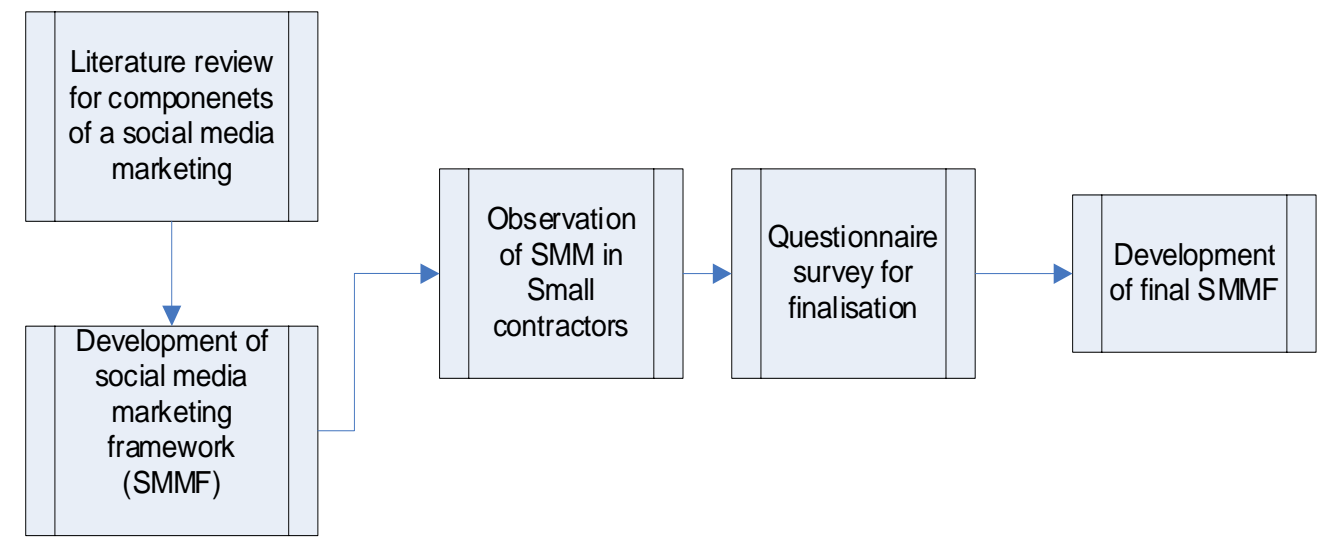

Figure 1. Research flow chart for social media marketing framework (SMMF) development. 


\subsection{Observations}

A structured observation sheet was used to collect data that is not readily captured by other methods of data collection such as surveys and interviews to establish how many times something actually happened in its natural setting (Saunders et al., 2009). The observation entails that there was need for examining the way social media marketing is practiced by some of the respondents earmarked for the survey. This was done by examining their online presence over various platforms, how frequently they make online posts and finding a way to relate that to their overall business. One example was to examine a particular firm's presence on Facebook and LinkedIn; the way they post and their interaction with their followers was critical to the analysis. The justification of the use of observations was that observations allow for uncorrupted information from the target population and further allow direct access to the innate way the respondent would approach a situation which is the main source of the information required. However, this mode of data collection can be quite involving and very tedious to go through hours of observation (Ross, 2005). The sample to be observed was sent as inquiries to ascertain willingness to participate in the study for pre-selection with the main criteria being some social media presence on platforms such as Facebook. Some of the items of interest for the observations for a particular organization were:

1) Number of followers;

2) Type of content frequently put out;

3) Description of content;

4) Frequency of content posting;

5) Frequency of response to complaints/comments from followers;

6) Nature of reviews from followers;

7) Connection service attached to the page;

8) Type of tone used in most posts;

9) Type of voice used in most posts;

10) Type of influencers used.

The survey used self-administered questionnaires for data collection. The justification behind the use of questionnaires was that questionnaires are comparatively convenient and less expensive compared to other methods of data collection (Ross, 2005); Secondly, questionnaires give great confidence to the respondents due to the anonymity, aspect of questionnaires; Thirdly, they increase the likelihood of obtaining accurate information in situations where sensitive questions are asked. Nevertheless, questionnaires have shortcomings such as lack of spontaneity in questions; the response rate of questionnaires can be very low at times hence the reduction in the sample size. Questionnaires need a sample size of respondents that is learned in addition to having reading and writing abilities. As a result, it is quite difficult to get information from the respondents (Ross, 2005). The nature of questions asked in the survey was of various types (closed and open in nature). Closed questions were either categorical (various platforms used, in- 
fluencers used, modes of listening, observing or monitoring) or scaled (has an effect, has no effect). The questionnaire had general information and a section dedicated to social media practices. The general information section was aimed at soliciting information on age range of the respondent and age of the firm, respondents' primary profession and the grade of the contractor. The section on SMM was on executive buy in, social media listening and monitoring, return on investment and other general marketing questions on budgets and crisis management.

\subsection{Final Framework}

The final framework was formulated after analyzing the survey and observations data. It was also crucial to have the proposed framework components verified for relevance by way of weighing. The highest weighting was 5 and lowest was 1 , the breakdown of each element is as follows; 5-Highly Relevant, 4-Relevant, 3-Moderately Relevant, 2-Not Relevant but should still be kept in the framework and $1-$ Not Relevant and can be removed from the framework.

\section{Results}

\subsection{Literature Review-Based Findings}

\subsubsection{Literature Review Findings on Components of a Social Media Marketing}

Lindberg (2009) describes the construction sector as one comprising five subsectors namely design (architects, engineers), assembly (contractors, builders' subcontractors and specialists, Clientele-Public, Private and international; and Manufacturing of material supply. Owing to the fact that the construction industry is unique in its composition, it requires a tailor-made framework that will match accurate social media marketing with the correlating return on investment. The focus of this research was on small sized contractors who had some form of social media marketing. The findings in this literature review section discuss aspects of the social media marketing before considering field data findings. Literature indicates that the Social Media Marketing Framework (SMMF) should constitute the following elements:

1) Executive buy-in stage (firm gets campaign funding and content) (Miliopoulou, 2019).

2) Budget development \& crisis management (Johansson et al., 2012; Kilian et al., 2012).

Table 1. Data collection details.

\begin{tabular}{lccccc}
\hline $\begin{array}{c}\text { Method of } \\
\text { data collection }\end{array}$ & $\begin{array}{c}\text { Population of } \\
\text { forms with some } \\
\text { for SMM }\end{array}$ & $\begin{array}{c}\text { Sampling } \\
\text { Technique }\end{array}$ & $\begin{array}{c}\text { Sample } \\
\text { size }\end{array}$ & Responses & $\begin{array}{c}\text { Response } \\
\text { rate }\end{array}$ \\
\hline Questionnaire & 35 & Purposive sampling & 32 & 21 & $60 \%$ \\
Observations & 35 & Purposive sampling & 35 & 35 & $100 \%$ \\
\hline
\end{tabular}


3) Social listening and monitoring (Dholakia et al., 2009; Pauley, 2015).

4) General rate of return on investment (ROI) evaluation stage (Bodnar \& Cohen, 2011).

\subsubsection{Executive Buy-in Stage (Firm Gets Campaign Funding)}

The executive buy in stage is focused on identifying the right buyer persona and target audience. There is a generic difference between a lead and a customer. A lead is a potential client who has the very traits that the entire campaign was targeting, while a customer is an actualized lead who is ready to go about making an exchange of money for the service at hand. Online campaigns and content structure are based on interactions and links between platforms with no dead ends hoping to keep consumers constantly engaged (Miliopoulou, 2019). Developing the right content for the right audience is cardinal for any firm including those in the construction sector. An example of the right buyer persona for a construction firm would be clients within a certain average income bracket. These particular clients can be found by using the right psychographics; because going beyond the demographics of your buyer persona and really understanding your clients can help differentiate your social media marketing from that of competitors (Michaelidou et al., 2011).

The social media-marketing framework should not only be built for the mere contractor who does ordinary jobs but also the highly advanced firm with contracts in different countries. This is accomplished by acknowledging that the social media framework helps in utilizing one of the strongest marketing strategies and that is "customer professional relationship". Moreover, there is also need to realize that clients react more to other clients than by direct marketing and that should also be taken into consideration. TrackMaven's (2016) also highlighted that content engagement needs to be precise thereby spreading the word in order to get the right audience. This therefore calls for selling the right key performance indicators and tools for a given channel of choice.

\subsubsection{Setting KPIs and Selecting the Right Tools for Each Channel}

Without the right parameters, any system would not operate well enough. According to Jeffrey (2013), a key performance indicator (KPI) is a quantifiable measure used to evaluate the success of a project in meeting objectives of performance. When dealing with social media marketing one needs KPI's to avoid vanity metrics. A vanity metric is a surface level number or statistic that looks great on paper but does not correlate to business success. An example of a vanity metric is the number of followers a construction firm has, also called a "fluffy metric" (Bodnar \& Cohen, 2011). The right social media KPI's to consider for a construction firm would be; reach and engagement, return and investment, and retention and loyalty.

Reach and engagement are very measurable metrics because they consider the number of consumers that actually took time to go to your social media page either on Facebook or any other platform and actually liked your work, com- 
mented or even went a step further to click on the web link to browse through the company site (Bodnar \& Cohen, 2011). This particular metric needs to be taken in collusion with other factors because it is very difficult to tell if one's engagement leads directly to sales (Elliott, 2014). The resultant of an engaged social media does however bring increased retention, share-of-wallet and consumer satisfaction that can be linked to return on investment from the social media marketing (Cummins et al., 2014).

Return on investment (ROI) is direct sales that came as a result of your online social media presence (Charlesworth, 2014). While these do exist, access to the social media does not directly translate into sales. Additionally, monitoring has to be done to ensure the right evaluation is made regarding online presence that would result in sales. The monitoring would also enable the firm to determine which customers have been returned and are loyal. Nonetheless, the construction industry may be characterized with one off clients who may only spread the word of your good service more among scale contractors.

Retention and loyalty can be measured as the number of clients that come back to your page every so often (Wolfinbarger \& Gilly, 2003). The very essence of having clients come back even after a couple of weeks or months or even years is termed as retention and loyalty, most loyal customers can be seen by their ability to take time to review your documents in post or even a video of any of the services that you have provided (Victoria, 2014).

General Social Media Platforms and Useful Tools; In order to have the right audience appropriate platform(s) and tool(s) must to be used. When selecting the right platform to start with, one can use Facebook, LinkedIn and Twitter as bases for their selection but these are not the only platforms that are available. Depending on your buyer persona, any of the above platforms can work but once your budget has been determined, you can make necessary adjustments. Every platform has its own unique settings and one needs to use the strategies for each respectively depending on your budget and business needs.

\subsubsection{Budget Development \& Crisis Management}

When setting a budget, it is essential to decide on whether one is going to outsource the necessary social media-marketing expert or entrust staff from within the organization will be entrusted to handle some or all of the work. Being able to match cost efficiency and marketing success is key when developing a budget; because the campaign is determined by the platform, the buyer persona in question and the overall amount of funds available (Victoria, 2014). Moreover, understanding that there is a link between traditional media and social media solves many budget allocation issues (Kilian et al., 2012). Out of the ordinary budget of marketing, a contingency budget for a crisis management needs to put in place for times of calamity such as an accident on one of your projects or a natural disaster. 


\subsubsection{Crisis Management}

Crisis management is the concept of putting certain predetermined measures in place before a calamity occurs on one of firms' social media platforms (Johansson et al., 2012). Some of the predetermined measures consist of having employees sign advocacy plan that control what and when they posted information about the firm on their private social media accounts. This regulates the way the information flows out of the firm to the public because an audience will trust an employee more than an audience will trust any personage or public relations officer who tries to smoothen a very lackadaisical situation. Crisis management goes a long way in maintaining brand parity in chaotic times (Salvador et al., 2017). The fact that a branded product is different from an unbranded build entails that measures need to be put in place to ensure the brand is maintained (Johansson et al., 2012; Koçak et al., 2007; Simon \& Sullivan, 1993; Wang, 2010).

\subsubsection{Content Generation Stage-Pre-Generation Analytics}

Before creating any content, it is very important that one looks back at other posts and review how they have affected their buyer persona. In the construction industry, there are many situations that can be reviewed prior to a new campaign being launched such as interest of the audience, questions posed, most liked post and so on. Whether the content is user generated or firm generated the content does impact on the consumer to a greater extent (Schivinski \& Dabrowski, 2016). As an example, if the firm had previously a campaign on roofing systems constructed by only using images from various sites that the firm is working on, even though the next campaign still keeps talking about roofs, introduction of videos and Graphic interface formats (GIFs) could turn out to be more effective. Revision is key to keep the audience interested (Coffey, 2001; Voeller, 2019). This therefore entails that an appropriate tone and voice is used to keep audience interested.

\subsubsection{Tone, Voice and Content Curation}

Voice is the unique, distinct expression of your brand through words while tone is the overall attitude of a piece of writing referring to how the voice is used in various situations (Kenny, 2017). While according to Gobl and Chasaide (2003), voice is the distinct and steady personality/style of your brand. Tone is a subset of voice; it refers to the moods and attributes of specific content pieces, which can change depending on the channel, the situation and the audience. Voice and tone can be classified as scientific, honest, humble, personal, dead and clinical (Tingley, 2015). The aspect of tone and voice turn your firm into brand because clients want to relate with other humans and not with machines in the natural sense (Kenny, 2017). When tone and voice are incorporated into your social media marketing a construction firm begins to humanize the brand, this further pushes the lead-to become a customer at a steady rate.

Sometimes the simplest thing can humanize your brand and improve sales (Blunt, 2018). Content curation is the ability to use content from other sources 
but pass it on to your audience as yours, of course by referencing the original authors. The fundamental benefit of this is that it helps ones brand earn respect because it tells the audience that you value the input of others but are humble enough to give credit to the rightful owners of the work. An example of content curation would be sharing certain articles/blogs of the newest technology being applied in the construction sector from a scientific body. Alteration of brand-image happens when word of mouth sharing or consumer-to-consumer discussions happens on the platform (Mangold \& Faulds, 2009; Schivinski \& Dabrowski, 2015). This is enabled by user generated content and influencer marketing.

\subsubsection{UGC and Influencer Marketing}

User Generated Content (UGC) is the art of having the very audience on your platform post content onto your page. Berger and Iyengar (2013) showed that this can be in the form of a campaign, but the important thing to realize is that the firm gets clients involved in the discussion. An example of UGCs includes the putting the word "challenge" at the end of a phrase; \#SafetyBootCHALLENGE or \#MySiteIsSafeCHALLENGE. These are examples of campaigns that promote safety on site, they may not necessarily bring about profit but they definitely fall in the corporate social responsibility bracket. Liu-Thompkins and Rogerson (2012) highlighted that because "hashtags" tend to be more entertaining, they are more likely to be shared by others. Influencer marketing is a slightly different variant from UGCs because a construction firm can use an influencer to help promote the brand. An influencer may not necessarily be a celebrity, but they must have some substantial pull over their niche whenever they talk about it on any social media platform. A good example, in Zambia is Trade Kings, which used a relatively unknown figure countrywide to talk about street vendors washing their hands with hand sanitizer because he is an activist of, keep the Zambia clean campaign on social media platforms. Schivinski and Dabrowski (2015) showed that UGCs are better than typical firm created content because they reach a wider audience in the process. Peralta (2019) demonstrated that using influencers and UGCs is important for the brand because of the following reason:

$>$ Procedures having been changing rapidly over the last few years,

> People trust recommendations from people they know over firms, and General Data Protection Rules (GDPR) on privacy limit brand exposure.

\subsubsection{Social Listening \& Monitoring Stage}

In social media marketing listening and monitoring are essential tools to ensure that the content can yield desired results (Pauley, 2015). This stage is important because it also helps to identify what others are doing and how effective what their engagement is.

\subsubsection{Listening and Monitoring Tools}

At this stage, it is imperative to pull out some sophisticated tools to aid the firm in 'listening and monitoring' its audience and how the audience has reacted to 
the content and strategies put in place (Dholakia et al., 2009). After all Quinton and Hardedge-March (2010) have promoted the idea of user generated content as useful though often ignored. If a firm is too outgoing without taking time to observe the effect of their actions, they risk running low yield campaigns (Saravanakumar \& Sugantha Lakshmi, 2012). Social listening aims to centralize everything about your brand in an easy way. Whilst social monitoring is actively looking to seek out mentions and conversations about your brand (Dholakia et al., 2009).

\subsection{Development of Proposed Social Media Marketing Framework}

Both listening and monitoring are important because they employ an outlook on the things that matter most like new opportunities and new innovation ideas, all of which ensure attention is derived from the consumer (Lepkowska-White, 2013). If during the monitoring phase, the firm, as a supplier, notices that people prefer Harvey tiles as a roof material they can invest more into procurement of that said commodity. It also helps to notice "super followers" who can be used as influencers for your brand. Free social listening tools include; Tweet deck, Facebook bookmark, Buzzsumo, Keyhole, and Tweet reach.

\subsubsection{Observing the Competition}

A client does not purchase products for one of two reasons; either they do not want it or they want it from a different source, this is what constitutes competition. It is therefore imperative to ensure that work is done to use social media to observe one's competition (Zahay et al., 2014). Taking note of one's competitors wins, losses, alliances/partnerships, reputation and marketing tactics can be used to inform the content development strategy being employed, the project delivery and the initial service offering/customer relation.

\subsubsection{General ROI Evaluation Stage}

The return on investment evaluation stage analyses key performance indicators by conducting an audit of social media and identifying leading indicators of success. Since return on investment or money saved are the only two metrics that really matter, it is important to note that it can be challenging without the right basis of measurement. In the first stage of the framework, it was stated that certain KPIs were important to keep an eye on (Jeffrey, 2013). When measuring return on investment from social media channels, the same KPIs used before ought to be maintained so as to avoid vanity metrics or fluffy metrics. The steps in conducting an ROI evaluation are as follows:

Conduct a social media audit. This is done by taking note of all social media channels used, the best and worst best performing platform/post, most engaged posts, click through content etc.

Leading indicators of success. Actual purchases made by clients that gained access through social media channels, reach \& engagement, Average sale value, 
pay per Click Valuation and finally the volume of resources saved through the campaigns. The ROI needs to be measured and some of the key free tools to use in measuring ROIs include; Crisp, Inbuilt analytics, Smart Moderation, and DataPine.com.

The literature reviewed was used to identify social media marketing needs which include: Executive by-in stage, Content generation stage, Social Listening and Monitoring Stage, and General ROI evaluation stage. From the synthesis of the literature, the framework in Figure 2 was developed and components were used as a basis of framework finalization.

\subsection{Questionnaire Survey for Finalization}

\subsubsection{Characteristics of Respondents}

Purposive sampling was used with 35 contractors who had social media presence from grades five and six, which mainly comprised SMEs. The respondents comprised contractors from construction management and quantity surveying background. 11/21 respondents willing participants in the survey were Grade 5 contractors while 10/21 comprised the contractors in grade 6 . For the observations, all 35 contractors using the social media for their marketing were observed and only $21 / 32$ took part in the survey.

For the survey, in terms of age, $33 \%$ of the respondents were aged 21 to 20 , $33 \%$ were aged between 26 - 40, and 23.8\% comprised those aged $41-60$ while those above 60 years comprised 9.5\%. Contractors' firm experience with 1 - 5 years accounted for $76.2 \%$, firms with 6 - 10 years' experience accounted for $4.8 \%$ of the respondents while those with existence of $11-15$ years accounted for $14.8 \%$. Firms above 16 years existence accounted for $4.8 \%$ of the respondents who were35 in number as already described.
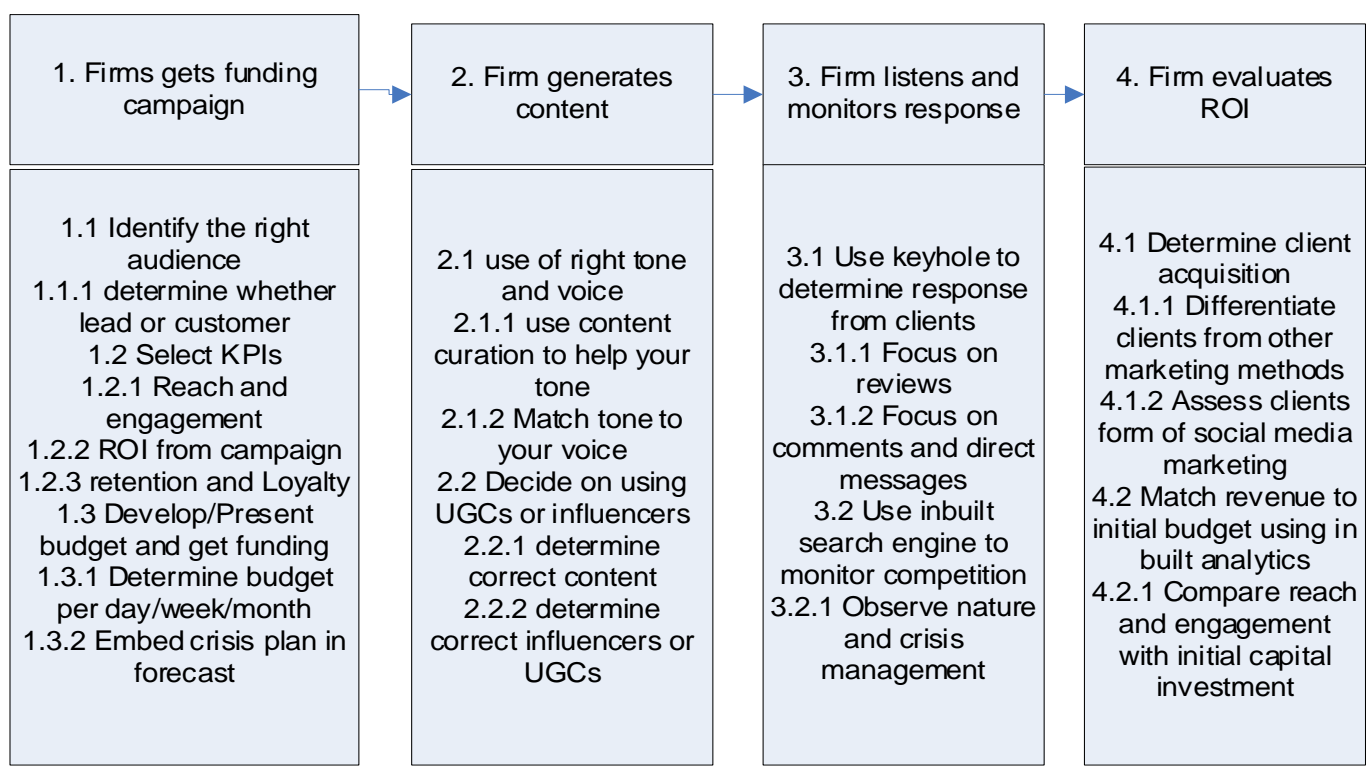

Figure 2. Proposed social media marketing framework (SMMF). 


\subsubsection{Current Use of Social Media Marketing Platform by Small-Scale Contractors}

The platforms used by SMEs in the construction sector in grade 5 and 6 from the observations are Facebook (95.2\%), Twitter 4.2\% and LinkedIn 9.5\%. These percentages are not cumulative but were taken based on the entire sample based on each platform independently. However, in the survey, when the contractors were asked the platforms where potential audience or target audience are found it was indicated that these could be found on various media as follows Facebook (85.7\%) Twitter (28.65\%), LinkedIn (9.5\%) and (9.6\%) on WhatsApp.

The frequency of posts was rated on a daily, weekly and monthly basis. The findings from the survey revealed that over half (68.3\%) post on a monthly basis, while $19.5 \%$ post on a weekly basis and $12.2 \%$ post on a daily basis. The observations showed some differences in posts as adverts with a 1-day life stood at $38.1 \%$, weekly was at $42.9 \%$ and monthly was at $28.6 \%$. The life of the adverts on the platforms also was rated on a daily weekly and monthly basis. Firms that kept the same advert daily accounted for $38.1 \%$, those that kept the advert for one week were $42.9 \%$ and those that kept it or a month stood at $28.6 \%$.

Costings for advertising related to the platforms used were up to K1000 for $81 \%$ of the respondents, $9.5 \%$ of the respondents spent between K1001 - K5000 and $9.5 \%$ spent over K5001. The management of the social media marketing was found to be in-house for most firms as indicated by $81 \%$ of the respondents and while only $19 \%$ outsourced the service.

\subsubsection{Audience and Budgeting}

For the firms practicing social media marketing and an array of target audiences have to be considered with various goals ranging from social to economic focus. Target audiences were found to be government agencies (33.3\%), non-governmental organizations (4.8\%), other construction firms (47.6\%), and general consumers (81\%) and those working with non-governmental organizations (4.8\%). To reach these target audiences budgets were found to be in the following ranges for the construction firms $\mathrm{K} 1-\mathrm{K} 1000$ at (81\% of the respondents), K1001 - K5000 (9.5\%) and above K5001 accounted for 9.5\%. The results clearly indicate that many firms do not significantly invest in their marketing. Many claimed that past works done would be adequate to get them future clients. Pheng et al. (2016) indicate that very few studies have been done on measuring the performance of marketing outcomes.

\subsubsection{Content, Tone and Voice}

In terms of type content SMEs in Zambia's' construction industry had Photographs (100\%), articles (29.3\%), videos (56.1\%) and GIFs (24.4\%). Descriptively the aforementioned type of content was found to be site progress (90\%), informative (65.9\%) and curative (26.8\%).

Figure 3 and Figure 4 highlighted that $97.1 \%$ of the respondents use direct

voice and tone. This translates to 34 out of 35 respondents. With the second 
Table 2. Target audience budgets budget.

\begin{tabular}{cc}
\hline Target & \\
\hline K1 - K1000 & $81 \%$ of the 35 contractors \\
K1001 - K1000 & $9.5 \%$ of the 35 contractors \\
Above 1 K5000 & 9.5 of the 35 contractors \\
\hline
\end{tabular}

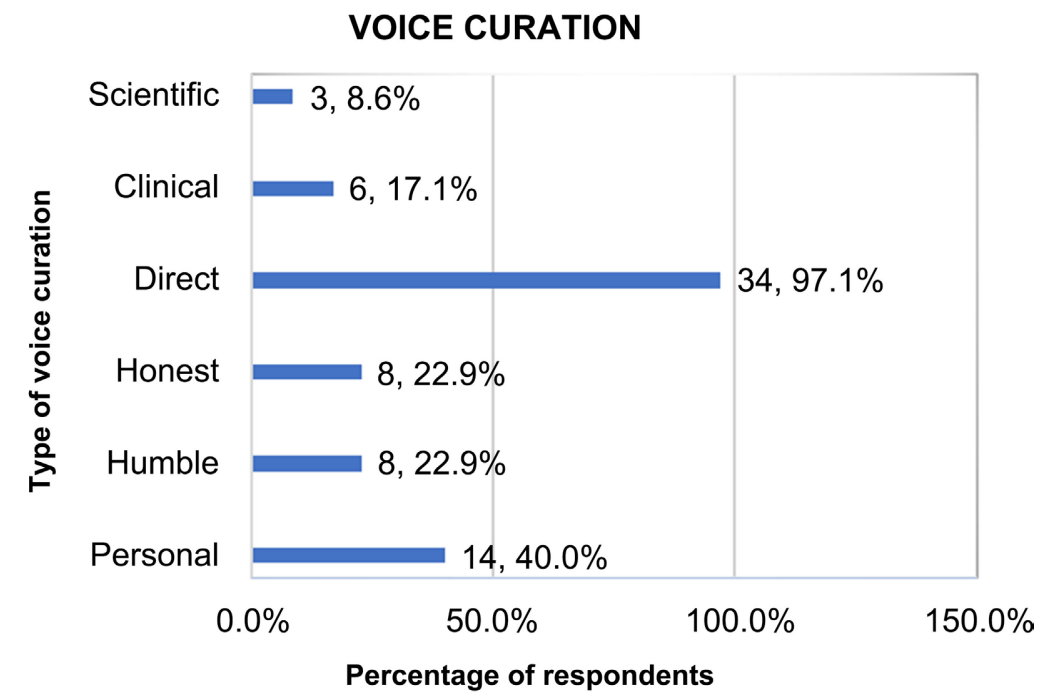

Figure 3. Voice used in the post.

TONE CURATION

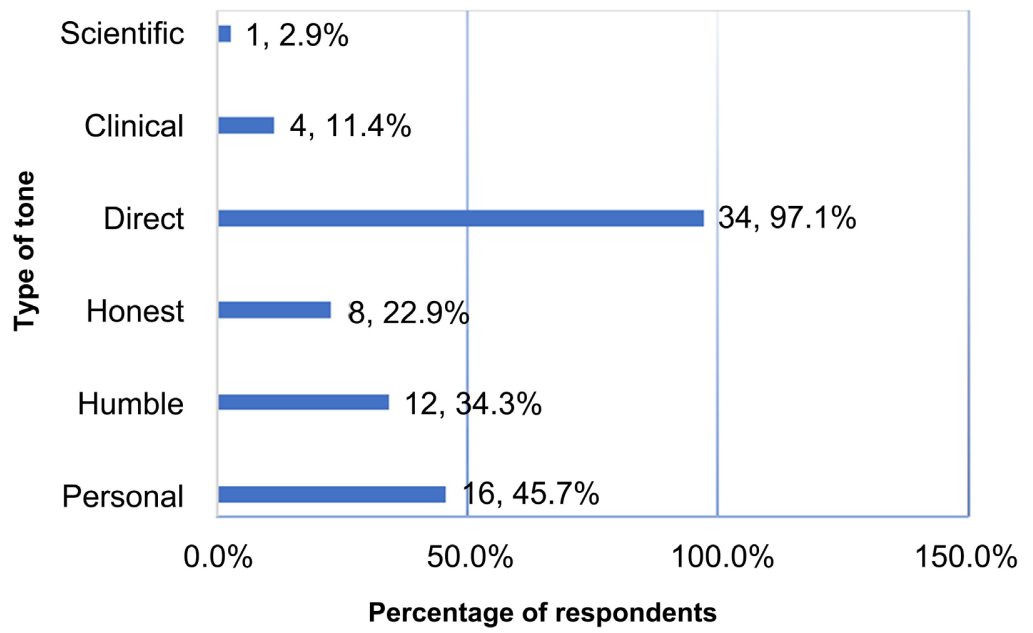

Figure 4. Tone used in the post.

most used type of voice and tone being Personal (40\% for voice and $45.7 \%$ for tone), it is evident why some of the pages are not growing as fast as they should be. This is because the very element of a direct voice and tone removes the "humanity" aspect of the post and begins to sound mechanical. Clients rarely resonate with a mechanic outlay; however, they do resonate with personal and humble voices and tones. 
One of the attractions of social media marketing is being able to deliver content with target audiences in various other modes. It is therefore it was expected from the observations that part of the content in the SMM was other connection services for the campaign. The SMM included websites (39\% of the respondents); phone numbers (92.7\% of the respondents), WhatsApp contact $(43.9 \%)$ while other firms had no further connection service (4.9\%). Further to this, the number of followers on the various media was shown. Less than half $(48.8 \%)$ had a following of less 500, 12.2\% and a following of $501-1000$ and 39\% had a following of above 1001 people. It must be noted that each platform was based on the total population of 35 respondents and therefore the percentages were not cumulative but independent for each platform chosen.

\subsubsection{Monitoring and Evaluation of Social Media}

One aspect of monitoring is being able to listen to target audience through responses or comments posted on the social media platforms. Slightly above half (52.4\%) indicated that listening aligned and improved their social media marketing, $19 \%$ stated that listening had no effect while 28.6 percent did not listen to their target audience.

When organizations spend money, it is expected that there would be benefits. $61.9 \%$ of the firms currently using social media marketing are convinced that they are benefiting from the social media marketing in terms of rate of return, $19 \%$ only did it to be visible as they did not observe any change in returns while $19 \%$ were unsure the benefits their campaigns were getting as they had no criteria of clearly linking clients to their campaign. Contractors were further asked to indicate clients that were attracted through social media marketing $14.3 \%$ indicated many, 33.3\% indicated moderate, $47.6 \%$ indicated few and $4.8 \%$ indicated none. It appears that the SMM is not attracting a high number of clients as perceived by users, as they have no deliberate way of monitoring the correlation between social media marketing and client acquisition.

\subsubsection{Major Elements of Framework after Survey and Observations}

Figure 2 shows the proposed framework for the Zambian construction industry. It is very similar to the frame work developed from the literature review; however, the main difference is the weighting of each element of the framework or the "relevance". Relevance is the importance of each element to the Zambian construction industry because the framework should be as practically usable as it can to the Zambian construction industry and therefore the following is the exact same framework but with a weighted illustration highlighting what is necessary as perceived by those currently using social media marketing. For instance, the highest rating was 5 and lowest was 1 , the breakdown of each element is as follows; 5-Highly relevant, 4-Relevant, 3-Moderately Relevant, 2-Not Relevant but should still be kept in the framework, and 1-Not relevant and can be removed from the framework. Figure 5 shows the various weightings as perceived from the survey of the component s of the framework. 


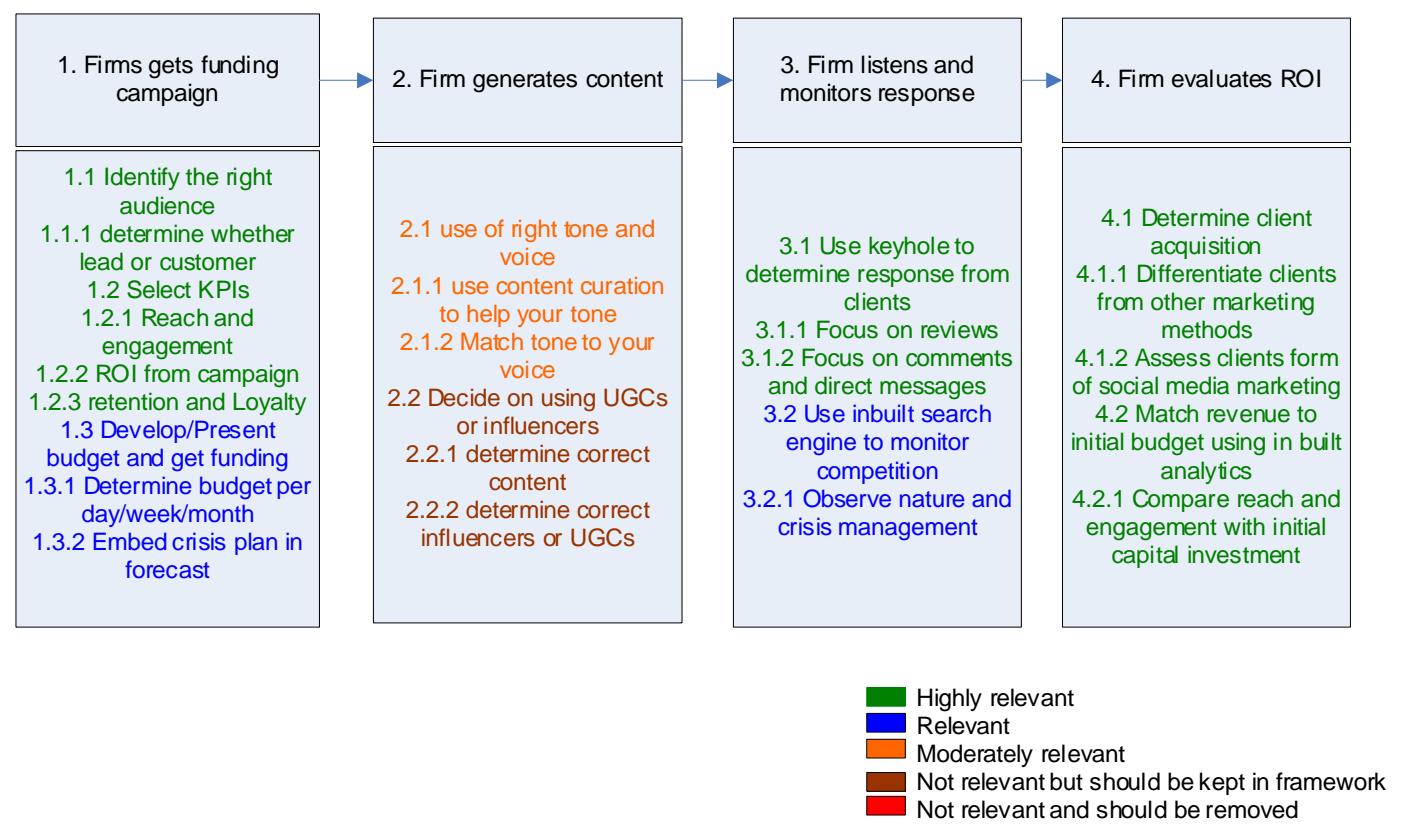

Figure 5. Final social media marketing framework for the Zambian construction industry.

\section{Discussion of Results}

Social media marketing is a very diverse topic with potentially confusing steps that all need to be followed for its effective implementation. The essence of this paper was to unravel the confusing steps and devise a simple yet effective framework that can be followed by any "construction layman" or small and medium enterprise that is engaged in marketing its product and services.

\subsection{Current Use of Social Media Marketing}

Small-scale contractors in Zambia like many other businesses using social media marketing use Facebook the most compared to any other social media platform. This is congruent to the findings of Golden (2010), Taylor and Strutton (2016); and De Vries et al. (2012), while the Social media marketing is aimed at reaching a wider audience, very little money in terms of budgeting is spent in the marketing process. The most common type of content was site progress (photos and videos) which are normally changed on a monthly basis. The reason that most contractors posted site photos and video was because it was the easiest type of content to generate. It could also be argued that for construction work, this is the kind of media that the audience can use to gauge the quality of works produced. However poor listening and monitoring means that the marketing technique is not generally audience driven but firm driven. Lepkowska-White (2013), Quinton (2013) and Quinton and Harridge-March (2010) advised that for successful marketing user generated content help in reaching out to a wider audience. The marketing could also be improved with a mix of outsourced and in-house marketing because small firms could rarely afford to out-source their marketing all the time. The average amount spent by most contractors was in the range of K13 
(1US) to K1000 (US77). Budgeting getting executive buy-in is not as hard because most firms can get their campaigns approved. However, most of the contractors use block advertising, (Once a month with same content) which is detrimental to their budgeting because spread advertising is a better option.

Almost all the construction firms have attached phone numbers to their social media channels. This shows that most if not all had a very serious mandate for going onto social media and to gain "profit and client acquisition". However, very few companies had influencers in terms of helping to draw traffic to their platform. Lee and Eastin (2021) argue that the use of influencers is key in social media marketing moreover the overall rating was that they are not relevant but should be included. User generated content however was not utilized at all. None use of UGCs in form of influencer has led to social media marketing not being used to the fullest, as people would rather believe people they are familiar with rather than firms. Schivinski and Dabrowski (2015) additionally add that UGCs aid in reaching a larger audience and therefore SMEs could reach more people with their campaigns by UGCs. The most used tone and voice are direct and personal, more often than not audiences usually identify with a humble tone that is not usually used. The tone and voice could be humble and show some empathy but show users some do-it-yourself guidelines on common home defects (how to care for s sticky door or problematic lock etc.) as this could in marketing solutions provided by the small-scale contractors.

\subsection{Components of a Social Media-Marketing Framework}

Having identified the components of a social medial marking from literature, the field survey was used to verify the components. The following were the highly relevant components from the survey Target Audience, Client Response Monitoring. Number of Clients Acquired and Measure of Return on Investment. K1 K1000 the aforementioned without question were seen as important aspects of the framework. Relevant and mandatory aspects were the Pre-Campaign Budget and Competition Monitoring. While those activities thought to be relevant but not mandatory were tone \& Voice and Influencers.

The social media marketing is budget driven as this determines the number of platforms and number of possible clients one can reach out to, nevertheless this is not an important aspect by most firms currently using SMM. Clear budgets need to be drawn with a specified target audience in term of numbers for the marketing to be successful. It would appear most small firms engage in social media marketing just to have digital presence and not necessarily to tap into their market share. Secondly monitoring what the competition is doing is key in ensuring that your content is more attractive and enticing to would be clients yet this is not considered as highly important. This type of attitude is only beneficial if you hold a monopoly in service delivery, which is rarely the case among most SMEs in construction. Influencers, appropriate tone and voice determine how often audiences come to listen to your campaign yet this is not considered as 
mandatory. Barcelos et al. (2018) argue that these are the fundamentals of social media marketing therefore, they need to be in the framework and should be mandatory and viewed as relevant.

\section{Conclusion}

Facebook is the most used social media marketing platform with videos and pictures being the most used content for small scale contractors using social media marketing in Zambia with a budget of between K13 (1US) and K1001 (US77). There is a need to include more platforms to reach more target audiences and use outsourced marketers to run the social media campaign who can post more than once a month. The tone and voice used should be humble, less direct and not personal to captivate would-be clients. In developing the framework, the highly relevant components were Target Audience, Client Response Monitoring, Number of Clients Acquired and Measure of Return on Investment. The aforementioned without question were seen as important aspects of the framework. Relevant and mandatory aspects were the Pre-Campaign Budget and Competition Monitoring while those activities thought to be relevant but not mandatory were tone, voice and influencers. The proposed social media marketing framework was verified using the survey and observations hence it can be concluded that the aspects included are relevant namely funding campaign; content generation; listening and monitoring; and evaluation of return on investment. Each stage is critically tied to the next and brings out a formidable response to the low retention rate problem brought about earlier. It gives the small to medium scale contractor in the Zambian construction an easy-to-follow guideline on how to handle their online social media presence. The major limitation of this study is that it is only generalizable to small-scale enterprises in the construction industry in countries similar to Zambia and other similar developing countries in terms of organization. Additionally, the framework is aimed at aiding the contractors' social media marketing of their services and not consultants such as architects, civil engineers, quantity surveys etc. who are legally restricted from marketing their services.

\section{Acknowledgements}

This research received no specific grant from any funding agency in the public, commercial, or not-for-profit sectors.

\section{Conflicts of Interest}

The authors declare no conflicts of interest regarding the publication of this paper.

\section{References}

Afolabi, A. O., Ojelabi, R. A., \& Oyeyipo, O. (2018). An Analysis of Social Media Market- 
ing of Indigenous Construction Firms in Nigeria: A Tool for Sustainable Growth. International Journal of Construction Supply Chain Management, 8, 60-72. https://doi.org/10.14424/ijcscm802018-60-72

Ahlqvist, T., Bäck, A., Halonen, M., \& Heinonen, S. (2008). Social Media Roadmaps: EXploring the Futures Triggered by Social Media. VTT Technical Research Centre of Finland.

Andrews, C. (2012). Social Media Recruitment. Applied Clinical Trials, 21, 32-42.

Barcelos, R. H., Dantas, D. C., \& Sénécal, S. (2018). Watch Your Tone: How a Brand's Tone of Voice on Social Media Influences Consumer Responses. Journal of Interactive Marketing, 41, 60-80. https://doi.org/10.1016/j.intmar.2017.10.001

Berger, J., \& Iyengar, R. (2013). Communication Channels and Word of Mouth: How the Medium Shapes the Message. Journal of Consumer Research, 40, 567-579. https://doi.org/10.1086/671345

Blunt, W. (2018, March 8). 9 Key Elements of an Effective Social Media Marketing Strategy, and How to Establish Them. Socaialmediatoday.

Bodnar, K., \& Cohen, J. L. (2011). The B2B Social Media Book: Become a Marketing Superstar by Generating Leads with Blogging, LinkedIn, Twitter, Facebook, Email, and more. John Wiley \& Sons.

Brown, M. (2012, February 16). Why the Construction Sector Should Engage with Social Media.

http://www.theguardian.com/sustainable-business/construction-sector-social-Media

Celuch, K., \& Murphy, G. (2010). SME Internet Use and Strategic Flexibility: The Moderating Effect of It Market Orientation. Journal of Marketing, 26, 131-145. https://doi.org/10.1080/02672570903574296

Charlesworth, A. (2014). Digital Marketing: A Practical Approach (2nd ed.). Routeledge. https://doi.org/10.4324/9780203493717

Coffey, S. (2001). Internet Audience Measurement: A Practitioner's View. Journal of Interactive Advertising, 1, 10-17. https://doi.org/10.1080/15252019.2001.10722047

Coleman, V. (2013). Social Media as a Primary Source: A Coming of Age. Educause Review, 48, 60-61.

Cummins, S., Peltier, J. W., Schibrowsky, J. A., \& Nill, A. (2014). Consumer Behavior in the Online Context. Journal of Research in Interactive Marketing, 8, 169-202. https://doi.org/10.1108/JRIM-04-2013-0019

De Vries, L., Gensler, S., \& Leeflang, P. S. (2012). Popularity of Brand Posts Brand Fan Pages an Investigation Effects Social Media Marketing. Journal of Interactive Marketing, 26, 83-91. https://doi.org/10.1016/j.intmar.2012.01.003

Dholakia, U. M., Blazevic, V., Wiertz, C. and Algesheimer, R. (2009). Communal Service Delivery: How Customers Benefit from Participation in Firm-Hosted Virtual P3 Communities. Journal of Service Research, 12, 208-226.

https://doi.org/10.1177/1094670509338618

Elliott, N. (2014, December 10). Want More Social Marketing Budget? Stop Measuring Social Engagement. Nate Elliott's Blog. http://blogs.forrester.com/nate elliott/14-12-10-want more social marketing budget stop measuring social engagement

Fulcher, G. (2014). Testing Second Language Speaking. Routledge. https://doi.org/10.4324/9781315837376 
Gobl, C., \& Chasaide, A. N. (2003). The Role of Voice Quality in Communicating Emotion, Mood and Attitude. Speech Communication, 40, 189-212. https://doi.org/10.1016/S0167-6393(02)00082-1

Golden, M. (2010). Social Media Strategies for Professionals and Their Firms: The Guide to Establishing Credibility and Accelerating Relationships. Wiley.

Grahl, T. (2015). The 6 Types of Social Media. http://timgrahl.com/the-6-types-of-social-media/

Han, B., \& Myers, C. (2018). Perceptions of Overuse, Underuse, and Change of Use of a Social Media Site: Definition, Measurement Instrument, and Their Managerial Impacts. Behaviour \& Information Technology, 37, 247-257. https://doi.org/10.1080/0144929X.2018.1432687

Hutter, K., Hautz, J., Dennhardt, S., \& Füller, J. (2013). The Impact of User Interactions in Social Media on Brand Awareness and Purchase Intention: The Case of MINI on Facebook. Journal of Product and Brand Management, 22, 342-351. https://doi.org/10.1108/JPBM-05-2013-0299

Järvinen, J., Tollinen, A., Karjaluoto, H., \& Jayawardhena, C. (2012). Digital and Social Media Marketing Usage in B2B Industrial Section. Marketing Management Journal, 22, 102-117.

Jeffrey, A. (2013). Social Media Measurement: A Step-by-Step Approach Using the AMEC Valid Metrics Framework. In 16th International Public Relations Research Conference (pp. 360-401). http://dx.doi.org/10.2139/ssrn.2335582

Johansson, J. K., Dimofte, C. V., \& Mazvancheryl, S. K. (2012). The Performance of Global Brands in the 2008 Financial Crisis: A Test of Two Brand Value Measures. International Journal of Research in Marketing, 29, 235-245.

https://doi.org/10.1016/j.ijresmar.2012.01.002

Kapata, C. (2018). Application of Porters Diamond Model in Nichie Identification for Small-Scale Contractors in Zambia. Unpublished Undergraduate Thesis, Copperbelt University.

Kenny, J. (2017). Know the Difference between Tone and Voice to Set Your Band apart. Blogging Content Marketing. http://www.gimmemojo.com

Kilian, T., Nadine, H., \& Sascha, L. (2012). Do Millennials Read Books or Blogs? Introducing a Media Usage Typology of the Internet Generation. Journal of Consumer Marketing, 29, 114-124. https://doi.org/10.1108/07363761211206366

Koçak, A., Abimbola, T., \& Özer, A. (2007). Consumer Brand Equity in a Cross-Cultural Replication: An Evaluation of a Scale. Journal of Marketing Management, 23, 157-173. https://doi.org/10.1362/026725707X178611

Kulemeka, P. J., Kululanga, G., \& Morton, D. (2015). Critical Factors Inhibiting Performance of Small and Medium Scale Contractors in Sub-Saharan Region: A Case of Malawi. Journal of Construction Engineering, 2015, Article ID: 927614. https://doi.org/10.1155/2015/927614

Lee, J.A., \& Eastin, M. S. (2021). Perceived Authenticity of Social Media Influencers: Scale Development and Validation. Journal of Research in Interactive Marketing, 15, 822-841. https://doi.org/10.1108/JRIM-12-2020-0253

Lepkowska-White, E. (2013). Are They Listening? Designing Online Recommendations for Today's Consumers. Journal of Research in Interactive Marketing, 7, 182-200. https://doi.org/10.1108/JRIM-07-2012-0027

Lindberg, D. (2009). Chinese Construction Investments in Africa: The Case of Zambia. 
Department of Economics, Stockholm School of Economics.

Lipita (2016, May 13). What is Web 2.0? Definition, Advantages and Features. https://www.znetlive.com

Liu-Thompkins, Y., \& Rogerson, M. (2012). Rising to Stardom: An Empirical Investigation of the Diffusion of User-Generated Content. Journal of Interactive Marketing, 26, 71-82. https://doi.org/10.1016/j.intmar.2011.11.003

Mangold, W. G., \& Faulds, D. J. (2009). Social Media: The New Hybrid Element of the Promotion Mix. Business Horizons, 52, 357-365.

https://doi.org/10.1016/j.bushor.2009.03.002

Michaelidou, N., Siamagka, N. T., \& Christodoulides, G. (2011). Usage, Barriers and Measurement of Social Media Marketing: An Exploratory Investigation of Small and Medium B2B Brands. Industrial Marketing Management, 40, 1153-1159. https://doi.org/10.1016/j.indmarman.2011.09.009

Miliopoulou, G.-Z. (2019). Revisiting Product Classification to Examine Content. Journal of Research in Interactive Marketing, 13, 492-508. https://doi.org/10.1108/JRIM-07-2018-0084

Mukherjee, K., \& Banerjee, N. (2019). Social Networking Sites and customers' Attitude towards Advertisements. Journal of Research in Interactive Marketing, 13, 477-491. https://doi.org/10.1108/JRIM-06-2018-0081

Naranjo, G., Pellicer, E., \& Yepes, V. (2011). Marketing in the Construction Industry: State of Knowledge and Current Trends. Dyna, 78, 250-258.

National Council Construction (2017). Annual Report-National Council Construction Report. National Council Construction. http://www.ncc.org.zm

O'reilly, T. (2005, September 30). What Is Web 2.0. http://www.oreilly.com/pub/a/web2/archive/what-is-web-20.html

Ojo, G. K. (2011). Effective Marketing Strategies and the Nigerian Construction Professionals. African Journal of Marketing Management, 3, 303-311.

Pauley, N. (2015). How the Top UK Construction Companies Are Using Social Media Marketing in 2015.

http://www.pauleycreative.co.uk/2014/01/how-thetop-construction-companies-are-usi ng-social-media-in-2015/

Peralta, R. L. (2019). How Vlogging Promotes a Destination Image: A Narrative Analysis of Popular Travel Vlogs about the Philippines. Place Branding and Public Diplomacy, 15, 244-256. https://doi.org/10.1057/s41254-019-00134-6

Pheng, L. S. (1994). Balancing Construction and Marketing in World Economic Development: The Four Global Scenarios. Construction Management and Economics, 12, 171-182. https://doi.org/10.1080/01446199400000023

Pheng, L. S., Gao, S., \& Mohdari, M. M. (2016). Marketing Importance and Marketing Performance Measurement of Architecture Firms in Singapore: An Exploratory Study. Construction Management and Economics, 34, 739-750. https://doi.org/10.1080/01446193.2016.1211719

Quinton, S. (2013). The Community Brand Paradigm: A Response to Brand Management's Dilemma in the Digital Era. Journal of Marketing Management, 29, 912-932. https://doi.org/10.1080/0267257X.2012.729072

Quinton, S., \& Harridge-March, S. (2010). Relationships in Online Communities: The Potential for Marketers. Journal of Research in Interactive Marketing, 4, 59-73. https://doi.org/10.1108/17505931011033560 
Republic of Zambia (2017). Seventh National Development Plan: 2017-2021.

Ross, K. (2005). Sample Design for Education Survey Research. United Nations Educational, Scientific and Cultural Organization (UNESCO).

Salcido, M. (2011). Benefits and Advantages of Using Social Media / Advantages of Social Media. http://www.organicseoconsultant.com/advantages-of-using-socialmedia/

Salvador, A. B., Ikeda, A. A., \& Crescitelli, E. (2017). Crisis Management and Its Impact on Brand Image. Gestão \& Produção, 24, 15-24.

https://doi.org/10.1590/0104-530x1668-14

Saravanakumar, M., \& SuganthaLakshmi, T. (2012). Social Media Marketing. Life Science Journal, 9, 4444-4451.

Saunders, M., Lewis, P., \& Thornhill, A. (2009). Research Methods for Business Studies (5th ed.). Pearson Education Limited.

Schivinski, B., \& Dabrowski, D. (2015). The Impact of Brand Communication on Brand Equity through Facebook. Journal of Research in Interactive Marketing, 9, 31-53. https://doi.org/10.1108/JRIM-02-2014-0007

Schivinski, B., \& Dabrowski, D. (2016). The Effect of Social Media Communication on Consumer Perceptions of Brands. Journal of Marketing Communications, 22, 189-214. https://doi.org/10.1080/13527266.2013.871323

Simon, C. J., \& Sullivan, M. W. (1993). The Measurement and Determinants of Brand Equity. A Financial Approach. Marketing Science, 12, 28-53.

https://doi.org/10.1287/mksc.12.1.28

Smith, A. N., Fischer, E., \& Chen, Y. (2012). How Does Brand-Related User-Generated Content Differ across YouTube, Facebook, and Twitter? Journal of Interactive Marketing, 26, 102-113. https://doi.org/10.1016/j.intmar.2012.01.002

Smyth, H., Fellows, R., Liu, A., \& Tijhuis, W. (2016). Editorial for the Special Issue on Business Development and Marketing in Construction. Construction Management and Economics, 34, 205-217. https://doi.org/10.1080/01446193.2016.1199370

Taylor, D. G., \& Strutton, D. (2016). Does Facebook Usage Lead to Conspicuous Consumption? The Role of Envy, Narcissism and Self-Promotion. Journal of Research in Interactive Marketing, 10, 231-248. https://doi.org/10.1108/JRIM-01-2015-0009

Thimmesch, M. (2010). http://www.skylinetradeshowtips.com/what-is-marketing-how-10-experts-define-it/

Tingley, C. (2015). Social Media Marketing Strategies to Engage Generation Y Consumers. Walden Dissertations and Doctorial Studies Collection, Walden University.

TrackMaven (2016). The Content Marketing Paradox Revisited: Time for a Reboot? http://trackmaven.com/resources/content-marketing-paradox-revisited/

Victoria, B. (2014). Customer Loyalty Activation through Online Direct Marketing. Bachelors Thesis, Laurea University of Applied Sciences.

Voeller, N. T. (2019). The Digital Sensorium: Considering the Senses in Website Design. Computers and Composition, 54, Article ID: 102508.

https://doi.org/10.1016/j.compcom.2019.102508

Wang, H.-M. D. (2010). Corporate Social Performance and Financial-Based Brand Equity. Journal of Product \& Brand Management, 19, 335-345.

https://doi.org/10.1108/10610421011068577

Wolfinbarger, M., \& Gilly, M. C. (2003). eTailQ: Dimensionalizing, Measuring and Predicting Etail Quality. Journal of Retailing, 79, 183-198. 
C. K. Tembo et al.

https://doi.org/10.1016/S0022-4359(03)00034-4

Zahay, D. (2014). Beyond Interactive Marketing. Journal of Research in Interactive Marketing, 8. https://doi.org/10.1108/JRIM-08-2014-0047 